\title{
BMJ Open How does general practitioner discontinuity affect healthcare utilisation? An observational cohort study of 2.4 million Norwegians 2007- 2017
}

\author{
Lena Janita Skarshaug (10 , ${ }^{1}$ Silje Lill Kaspersen, ${ }^{1,2}$ Johan Håkon Bjørngaard, ${ }^{1,3}$ \\ Kristine Pape ${ }^{1}$
}

To cite: Skarshaug LJ, Kaspersen SL, Bjørngaard JH, et al. How does general practitioner discontinuity affect healthcare utilisation? An observational cohort study of 2.4 million Norwegians 2007-2017. BMJ Open 2021;11:e042391. doi:10.1136/ bmjopen-2020-042391

- Prepublication history and additional material for this paper are available online. To view these files, please visit the journal online (http://dx.doi. org/10.1136/bmjopen-2020042391).

Received 06 July 2020 Revised 10 January 2021 Accepted 26 January 2021

Check for updates

(c) Author(s) (or their employer(s)) 2021. Re-use permitted under CC BY-NC. No commercial re-use. See rights and permissions. Published by BMJ.

${ }^{1}$ Department of Public Health and Nursing, Norwegian University of Science and Technology, Trondheim, Norway ${ }^{2}$ Digital, SINTEF, Trondheim,

Norway

${ }^{3}$ Faculty of Nursing and Health Sciences, Nord Universitet Levanger Campus, Levanger, Norway

Correspondence to MD PhD Lena Janita Skarshaug; lena.j.skarshaug@ntnu.no

\section{ABSTRACT}

Objectives Patients may benefit from continuity of care by a personal physician general practitioner (GP), but there are few studies on consequences of a break in continuity of GP. Investigate how a sudden discontinuity of GP care affects their list patients' regular GP consultations, outof-hours consultations and acute hospital admissions, including admissions for ambulatory care sensitive conditions (ACSC).

Design Cohort study linking person-level national register data on use of health services and GP affiliation with data on GP activity and GP characteristics.

Setting Primary care.

Participants 2409409 Norwegians assigned to the patient lists of 2560 regular GPs who, after 12 months of stable practice, had a sudden discontinuity of practice lasting two or more months between 2007 and 2017.

Primary and secondary outcome measures Monthly GP consultations, out-of-hours consultations, acute hospital admissions and ACSC admissions in periods during and 12 months after the discontinuity, compared with the 12-month period before the discontinuity using logistic regression models.

Results All patient age groups had a $3 \%-5 \%$ decreased odds of monthly regular GP consultations during the discontinuity. Odds of monthly out-of-hours consultations increased $2 \%-6 \%$ during the discontinuity for all adult age groups. A $7 \%-9 \%$ increase in odds of ACSC admissions during the period 1-6 months after discontinuity was indicated in patients over the age of 65 , but in general little or no change in acute hospital admissions was observed during or after the period of discontinuity.

Conclusions Modest changes in health service use were observed during and after a sudden discontinuity in practice among patients with a previously stable regular GP. Older patients seem sensitive to increased acute hospital admissions in the absence of their personal GP.

\section{BACKGROUND}

Loosing access to your general practitioner (GP) can be emotionally stressful, ${ }^{1}$ and patients can be vulnerable during the
Strengths and limitations of this study

- This study was based on person-level registry data on the entire Norwegian population and their general practitioners (GPS) in the period 2007-2017.

- We had exact dates and objectivity in the ascertainment of outcomes (GP consultations, out-of-hours consultations, acute hospital admissions) and strict criteria for exposure (discontinuity of GP care).

- By following the same patient population over time, we eliminated time-invariant or slow-varying confounding factors related to the composition of patient groups.

- It is possible that the consequences of discontinuity would differ according to the causes of the break, which we were unable to measure due to lack of data.

transition of care from one GP to another. ${ }^{2}$ Some discontinuities of GP practice are inevitable, as GPs retire, get sick and take parental leave. A study on American patients forced to change their physician due to healthcare insurance changes, indicated this disruption to be damaging to the patient receipt of quality GP care. ${ }^{3}$ Continuity of care is a core value of primary care and general practice, including personal, informational and managerial aspects of continuity. ${ }^{4}$ An extensive literature suggest that high continuity of care in general practice reduces hospital admissions, ${ }^{5-12}$ readmissions, ${ }^{13}$ out-of-hours service visits, ${ }^{14-16}$ mortality ${ }^{17-20}$ and healthcare costs, ${ }^{21}$ but there is little research on how a break in this continuity of care affect patients.

Patients who experience such discontinuity may have reduced access to regular GPs during office hours and shift to out-ofhours services. Also, not being able to see their regular GP could lead to an increase in 
avoidable hospital admissions, as the regular GP would be better suited to do a proper assessment of both the medical conditions and the patient's total situation, including alternatives to hospital admission.

The establishment of the Norwegian regular GP scheme in 2001 introduced a structural emphasis on continuity of GP care by entitling all inhabitants to a regular GP within a list-based system, ${ }^{22}$ aiming to ensure health services with high availability and continuity for all inhabitants, including vulnerable and marginalised groups. ${ }^{23}$ This system has shown the ability to provide a high degree of personal GP continuity. ${ }^{24}$

We used Norwegian register data to design a study comparing healthcare use in populations differing in the continuity of GP care. We identified all registered list patients of contracted GPs with a stable practice pattern who suddenly stopped meeting patients for at least 2 months. Regardless of the reasons for such GP discontinuity, the list patients had to seek help from other physicians in the period when their GP was temporarily or permanently gone. Synchronisation of all patient timelines when their GP had a discontinuity of practice allowed us to assess the use of primary and specialist healthcare services around the time of discontinuitycomparing the entire patient population during and after the discontinuity to itself during a control period before the discontinuity. Thus, the study aimed to investigate if exposure to GP discontinuity would decrease patients' use of any regular GP but increase their use of the out-of-hours services and potentially also the need for acute hospital admissions.

\section{METHODS}

\section{The Norwegian context}

Primary care in Norway is organised by the municipalities and includes regular GP services during office hours and out-of-hours services (partly staffed by regular GPs) for emergency medical help. Like the UK, ${ }^{25}$ Norway practices a high level of primary care gatekeeping. Specialist care is generally possible only after a referral from a GP, except for emergency admissions. Health services coverage is universal for all Norwegian residents. Most GPs work in group practices (on average 93\% in 2010-2019),${ }^{26}$ most as self-employed (reimbursed by the national insurance system in addition to out-of-pocket payments from patients) and some on fixed salary from the municipality. The use of locums is increasing in Norway. Last quartal of 2018, $21 \%$ of all GP practises had been served by a locum, steadily increasing from 12.4\% in 2016 (no older data available). ${ }^{27}$

\section{Study design and data}

This study has a longitudinal design with person-level data from Norwegian national registers on the entire population during the period 2007-2017. We combined demographical information from Statistics Norway ${ }^{28}$ with several Norwegian national registers: the Control and Payment of Health Reimbursement register (KUHR) ${ }^{29}$ (on regular and out-of-hours consultations with GPs), the Norwegian GP Register ${ }^{30}$ (on GP affiliation, patient list information, individual GP characteristics) and the Norwegian Patient Register ${ }^{31}$ (on acute hospital admissions). Linkage of person-level data from different sources was possible by the identification number unique to all Norwegian inhabitants. Individuals were linked to their appointed regular GP, and each GP's doctor ID allowed identification of GP activity and characteristics.

\section{Study population}

The study population comprised all persons registered as list patients of the GPs with an episode of practice discontinuity (GP population) during the month 12 months prior to the time of discontinuity (population in figure 1A).

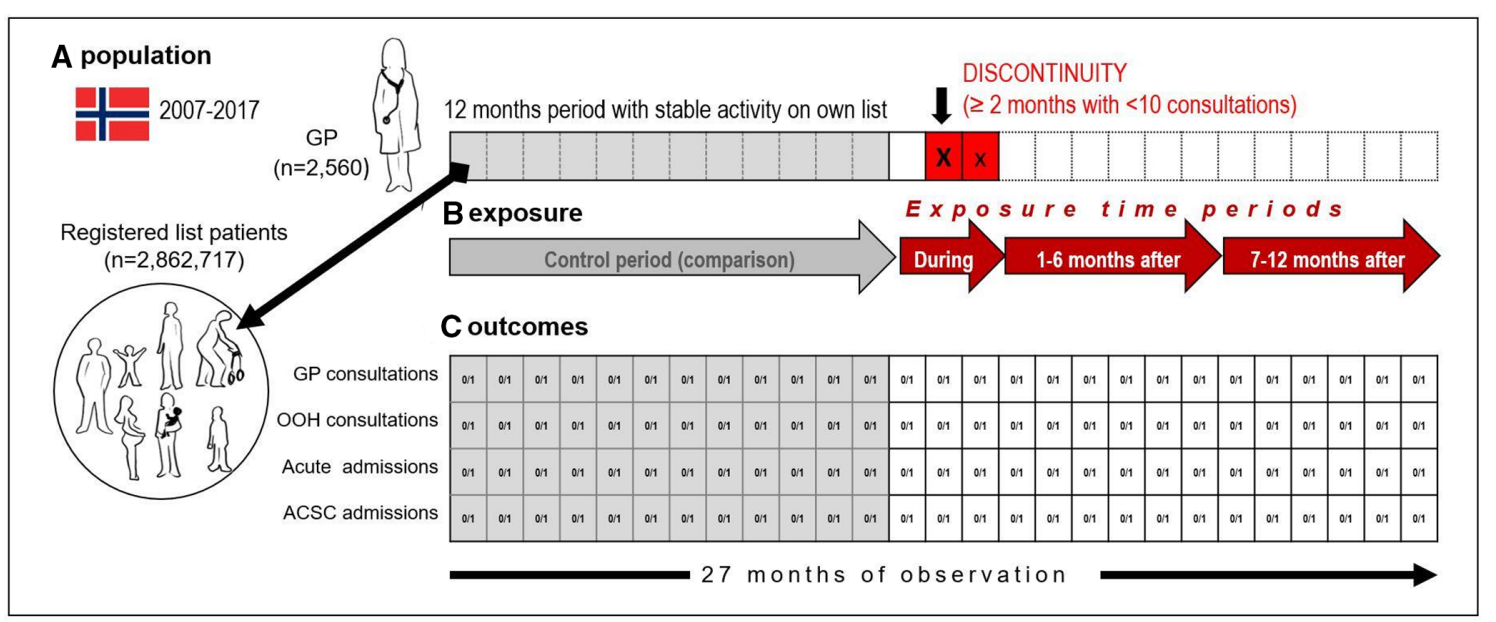

Figure 1 Illustration of study design and timeline for (A) study population and GPs, (B) definition of control period (12 months of stable GP activity on own patient list), exposure time periods during (3-month period defined discontinuity with at least 2 months with no/low activity $(\mathrm{X})$ ), 1-6 months after discontinuity and 7-12 months after discontinuity and (C) patient outcome assessment (four outcomes) in our four defined periods. ACSC, ambulatory care sensitive conditions; GP, general practitioner; $\mathrm{OOH}$, out-of-hours. 
Each time a GP is in contact with a patient, a claim for reimbursement is submitted to the Norwegian Health Economics Administration. This claim includes patient ID, time, type of contact, patient diagnosis and information about the GP. These claims are collected in the KUHR database-where both individual patients and doctors may be identified through identification numbers.

For all GPs, we assessed the number of submitted reimbursement claims for ordinary consultations (code 2ad) in the KUHR data each month in the period 2007-2017. We linked the monthly registrations on consultation activity to monthly information on the GP practice characteristics from the Norwegian GP Register. Episodes of two or more consecutive months with less than 10 consultations per month were identified as discontinuities (see figure 1).

We only included episodes of discontinuity for regular GPs registered as owners of lists identified with a unique list ID (excluding locums, interns, number of GP episodes $=5610$ ) and who had a stable practice on that same list during at least 12 months prior to the break, and none of these months with less than 10 consultations (excluding 2694 episodes). Furthermore, we excluded 326 episodes for GPs registered with short lists $(<500$ patients) or low activity during the 12 months before the break $(<1000$ consultations or ratio $<1$ for the total number of consultations the last 12 months/registered list size). For each doctor, we only kept the first episode of discontinuity (whereas patients could experience several episodes), removing 492 episodes. The final study population consisted of 2560 GP's and all patients registered on their lists at the time point 12 months before the discontinuity—in total 2862717 patient episodes.

\section{Exposure time periods}

We defined three exposure periods in relation to the time of discontinuity (exposure in figure 1B); the period defining the discontinuity itself (two consecutive months with no/low practice and the preceding month, a likely starting point of the break since GP activity was measured by calendar month) and the 12 following months divided into two 6-month periods. The period before discontinuity served as a control/comparison period.

\section{Outcome/Healthcare use and follow-up}

Our main outcomes were patients' monthly regular GP consultations, out-of-hours consultations, acute hospital admissions and ambulatory care sensitive conditions (ACSC) admissions. Patient follow-up started 12 months before the discontinuity when identified as list patient of GPs with a later practice discontinuity.

For each patient, healthcare use was assessed during 27 consecutive months (dichotomised measure of use/no use for each month (figure 1C)) - providing 27 monthly repeated observations per patient unless they died or emigrated. Regular and out-of-hours GP consultations were identified by the reimbursement code for a regular GP consultation (code $2 \mathrm{ad}^{32}$ ) and a GP consultation outside normal working hours (code $2 \mathrm{ak}^{32}$ ) from 2006 to 2017. Acute (unplanned) hospital admissions were identified in the Norwegian Patient Registry from 2008 to 2016, using the dates of admission and discharge for hospital stays that were coded as acute. ${ }^{31}$ We also used International Classification of Disease (ICD-10) diagnosis codes to identify hospital stays for ACSC. These are conditions for which hospitalisation is thought to be avoidable with the application of preventive care and early disease management, usually delivered in ambulatory settings. ${ }^{33}$ We included chronic conditions for which effective management prevents flare-ups (angina pectoris, asthma, chronic obstructive pulmonary disease, congestive heart failure, convulsions/epilepsy, diabetes complications, hypertension, iron deficiency anaemia), acute conditions for which early intervention may prevent more serious progression (ear, nose and throat infections, cellulitis, pyelonephritis, dehydration/gastroenteritis, pelvic inflammatory disease, gangrene, dental conditions, nutritional deficiencies, perforated/bleeding ulcer) and vaccine-preventable conditions (Influenza, pneumonia and other)—using National Health Service Digital's ICD-10 codes for ACSC episodes. ${ }^{34}$

\section{Covariates}

We collected information on patient birth year, sex, education and date for migration or death from Statistics Norway. ${ }^{28}$ The highest achieved level of education by 2016 was measured in three categories: 'no/primary school', 'secondary school' and 'college/university'. GP characteristics before the episode of discontinuity (assessed in the first month of the control period, 12 months before the discontinuity) were available from the Norwegian GP Register ${ }^{31}$ and included the GPs' sex and age, list size and municipality. Information on patient health prior to follow-up was collected by monthly assessments of selected health indicators from the KUHR ${ }^{29}$ and the Norwegian Patient Register. ${ }^{31}$

\section{Analyses}

We used generalised estimation equation ${ }^{35}$ models with repeated (maximum 27) monthly observations within patients within GPs, to estimate ORs of monthly use of health services during the three exposure periods (at the time of discontinuity, 1-6 months after and 7-12 months after), comparing the patient population with itself during the control period before discontinuity (12-month period before). Analyses were repeated for each of the four outcome measures; monthly regular GP consultations, out-of-hours consultations, acute hospital admissions and ACSC admissions. Patients were divided into categories according to their age at discontinuity $(0-18,19-44,45-64,65-79$ and $80+$ years $)$, and all analyses were repeated for each category separately. We adjusted for patient sex and the patient age (in years, categorical variable) at baseline within each age group. We also adjusted for observation calendar month (categorical variable) and calendar year (categorical variable) 
in order to take into account confounding from periodic and secular trends. Finally, we adjusted for increasing age (time passing) during follow-up (continuous variable measuring number of months after follow-up (ranging from 0 to 27 months) in order to adjust for confounding by increasing age within the follow-up period, since age is likely to increase use of services rapidly among the elderly.

In addition, we performed analyses on the patient subgroups with hypertension, ischaemic heart disease, mental illness and prior hospital stay. Patient's health status was assessed during a 12-month period prior to the control period (for these analyses defined by the 6-month period before discontinuity, see online supplemental figure 1). We identified four subgroups for which we considered continuity of care to be of particular benefit: (1) Hypertension-all patients having one or more diagnoses of hypertension (International Classification of Primary Care (ICPC-2) diagnosis K85-87) in the KUHR data; (2) Ischaemic heart disease-all patients having one or more diagnoses of (ICPC-2 diagnosis K74-80) in the KUHR data and (3) Mental illness-all patients having one or more diagnoses of (ICPC-2 diagnosis P70-P99) in the KUHR data and (4) Acute hospital stay-all patients having one or more acute hospital stay.

Patients were censored on the exact month of migration or death and at 31 December 2016. We performed all analyses with STATA V.15.1. Precision was presented with $95 \%$ CIs using robust standard errors and taking into account clustering of information within patients within the same GP.

\section{Patient and public involvement}

Patients and/or the public were not involved in the development of the research question, study design or interpretation of the data.

\section{RESULTS}

In the period 2007-2016, a total of 2409409 patients were registered as list patients of our selection of 2560 unique regular GPs with a stable practice, but who 12 months later had an episode of discontinuity. The number of patient episodes of discontinuity was 2862 717, as each patient could experience several episodes of discontinuity related to different GPs; $85 \%$ had one episode, $99 \%$ had one or two episodes, and the maximum number of episodes was five (data not shown). For baseline GP and patient characteristics, see table 1 . Patient healthcare use during the year prior to follow-up is available as online supplemental table 1.

As seen in table 2, patients in all age groups had a $3 \%-5 \%$ decreased odds of monthly regular GP consultation during the discontinuity, compared with the control period before the discontinuity. Most age groups then had a normalisation after the discontinuity. Compared with the control period before the discontinuity, all adult age groups had a $2 \%-6 \%$ increased odds of monthly outof-hours consultations during the discontinuity, which remained elevated after the discontinuity for most age groups. In general, there was little or no difference in acute hospital admissions during or after the period of discontinuity, but some evidence of an increase in ACSC admissions after discontinuity in patients over the age of 65. In the age group 65-79 years, the odds for ACSC admissions increased $7 \%-11 \%$ after discontinuity (OR $1.07,95 \%$ CI 1.01 to 1.14 and OR $1.11,95 \%$ CI 1.01 to 1.21 for periods 1-6 months and 7-12 months after discontinuity) compared with the period before discontinuity. These findings are also illustrated by the estimated absolute levels of healthcare use (regular GP consultation, out-of-hours consultation, acute hospital admission and ACSC admission) for each month during follow-up in online supplemental figures $2-5$. These figures show the underlying trends for each age group, in addition to level changes of healthcare use during and after the discontinuity, corresponding to main findings (table 2).

\section{Subgroup analysis}

Separate analyses on subgroups according to patient health status prior to follow-up (hypertension, ischaemic heart disease, mental illness and previously hospitalised) are shown in online supplemental tables 2-4). Compared with the main analysis, the subgroup analysis on patients with hypertension and ischaemic heart disease showed only marginal differences, but with somewhat more decreased OR of GP consultations during discontinuity, followed by normalisation. Patients with previous hypertension aged 65-79 had an increasing OR for out-of-hours consultations during and after discontinuity. For example, in the main analysis patients aged 65-79 had an OR 1.06 (95\% CI 1.02 to 1.09 ) for monthly out-of-hours consultations 1-6 months after discontinuity, whereas patients with hypertension had an OR 1.13 (95\% CI 1.02 to 1.24 ). For patients with previous ischaemic heart disease the largest differences between main and subgroup analyses applied to those aged 45-64 years who had decreased OR for ACSC acute hospital admissions during and the first period after discontinuity in the subgroup analysis, whereas those aged 65-79 years had more increased OR for ACSC acute hospital admissions in the subgroup analysis, compared with the main analysis. Previously hospitalised in the age group 80+ had increased OR for acute hospital admissions compared with patients included in the main analysis, particularly ACSC admissions. For example, in the main analysis, patients aged $80+$ had an OR 1.09 (95\% CI 1.02 to 1.16) for monthly ACSC hospital admissions 1-6 months after discontinuity, whereas previously hospitalised patients had an OR 1.24 (95\% CI 1.08 to 1.43 ).

\section{DISCUSSION}

\section{Summary}

In this study, we followed all Norwegian inhabitants registered as list patients of stable practising GPs who experienced one or more episodes of sudden discontinuity 
Table 1 Study sample with baseline characteristics of selected GPs with an episode of discontinuity in an earlier stable practice and their list patients (2007-2017)

\begin{tabular}{|c|c|c|c|}
\hline & \multicolumn{2}{|l|}{$\mathbf{N}$} & $\%$ \\
\hline \multicolumn{4}{|l|}{ GP characteristics* } \\
\hline Total & \multicolumn{2}{|l|}{2560} & 100 \\
\hline \multicolumn{4}{|l|}{ GP sex } \\
\hline Female & \multicolumn{2}{|l|}{1084} & 42 \\
\hline Male & \multicolumn{2}{|l|}{1476} & 58 \\
\hline \multicolumn{4}{|l|}{ GP age at discontinuity } \\
\hline$<30$ & \multicolumn{2}{|l|}{22} & 1 \\
\hline 30-39 & \multicolumn{2}{|l|}{1010} & 39 \\
\hline $40-49$ & \multicolumn{2}{|l|}{548} & 21 \\
\hline $50-59$ & \multicolumn{2}{|l|}{431} & 17 \\
\hline $60+$ & 549 & 21 & \\
\hline GP in group practice & 2244 & 88 & \\
\hline GP activity before discontinuity & & & \\
\hline Registered list size-mean number of patients (range) & 1126 & $500-2$ & 2483 \\
\hline $\begin{array}{l}\text { Mean no of ordinary patient consultations during } 12 \text { months before } \\
\text { discontinuity (range) }\end{array}$ & 2657 & 1000 & -10530 \\
\hline GP activity 12 months after discontinuity & & & \\
\hline Registered with same list ID as before & 1586 & 62 & \\
\hline Registered with same list ID as before and active ( $>10$ consultations) & 1112 & 43 & \\
\hline $\begin{array}{l}\text { Registered with same list ID as before and normal activity (number of } \\
\text { consultations } \geq 75 \% \text { compared with } 12 \text { months before discontinuity) }\end{array}$ & 813 & 32 & \\
\hline Patient episode characteristics* & & & \\
\hline Patient episodes $†$ & 2862717 & 100 & \\
\hline Sex & & & \\
\hline Female & 1441798 & 50.4 & \\
\hline Male & 1420919 & 49.6 & \\
\hline Age groups & & & \\
\hline $0-18$ & 614576 & 21.5 & \\
\hline $19-44$ & 1026774 & 35.9 & \\
\hline $46-64$ & 729031 & 25.5 & \\
\hline $65-79$ & 339833 & 11.9 & \\
\hline $80+$ & 152503 & 5.3 & \\
\hline Educational levelł & & & \\
\hline Primary & 680098 & 27.8 & \\
\hline Secondary & 1014323 & $41.5 ?$ & \\
\hline Tertiary & 752697 & 30.8 & \\
\hline Geography§ & & & \\
\hline Municipality $<2000$ inhabitants & 55576 & 2 (of $t$ & otal) \\
\hline 10 most populated municipalities & 892857 & 31 (of & total) \\
\hline $\begin{array}{l}\text { Monthly health service contact (age } \\
\text { groups, \% with at least one) }\end{array}$ & Out-of-hours & Acute admission & $\begin{array}{l}\text { ACSC } \\
\text { admission }\end{array}$ \\
\hline $0-18$ & 2.0 & 0.3 & 0.07 \\
\hline $19-44$ & 1.5 & 0.7 & 0.04 \\
\hline $46-64$ & 1.1 & 0.7 & 0.11 \\
\hline $65-79$ & 1.2 & 1.5 & 0.34 \\
\hline
\end{tabular}


Table 1 Continued

Monthly health service contact (age groups, $\%$ with at least one)
Regular GP

30.3
Out-of-hours

1.8
ACSC

Acute admission admission

0.85

*Patient and GP characteristics were identified 12 months before the identified discontinuity, unless otherwise stated. †Incidents of discontinuity of care. Some patient could experience several episodes of discontinuity during our observation time, and hence be counted more than once.

‡Educational level measured in 2016.

§Municipality in which the patient's GP was registered. Municipality size per 2. quarter of 2019.

ACSC, ambulatory care sensitive conditions; GP, general practitioner.

of GP care between 2007 and 2017. We found that all patient age groups had a small dip in regular GP consultations at the time of discontinuity compared with before the discontinuity, followed by normalisation for all adult groups. Out-of-hours consultations increased at the time of discontinuity for all adult groups compared with before the discontinuity and remained elevated during the following 12 months for those aged 19-44 years, 65-79 years and $80+$ years. An increase in ACSC admissions after discontinuity was indicated in patients over the age of 65 , but in general little or no differences in acute hospital admissions were observed during or after the period of discontinuity.

\section{Strengths and limitations}

We used a linkage of several registries, providing personlevel data on the entire Norwegian population and their GPs within a rather long observation period, which provided relatively precise estimates, even in the separate subgroup analyses. The Norwegian GP scheme with $<1 \%$ non-participants since the start in $2001^{36}$ made it possible to link each individual in the population to their regular GP. By including all patients 12 months before the break in GP continuity, we did not condition on the patient surviving until discontinuity. Hence, we did not miss some of the acute (potentially fatal) hospital admissions in our observation time before the discontinuity, thereby avoiding immortal time bias. ${ }^{37}$

We had exact dates and objectivity in the ascertainment of outcomes (GP consultations, out-of-hours consultations, acute hospital admissions) and strict criteria for exposure (discontinuity of GP care). We assessed the changes in outcome by following the same patient population over time. By design, we thereby eliminated all time-invariant or slow-varying confounding factors related to the composition of patient lists (groups), including morbidity, help-seeking behaviour, sex and education. There are numerous causes of a break in the GP practice (parental leave, mandatory practice for specialisation in general practice medicine, retirement, job change, GP sickness or death, etc), resulting in discontinuity for a shorter or longer period. It is possible that the consequences of discontinuity would differ according to the causes of the break (eg, planning, speed of replacement, single or group practice). Also, our results primarily apply to situations with a sudden discontinuity of practice, and not necessarily to situations characterised by a constant instability or more gradual changes. As we present several estimates as sensitivity analyses in this paper, one should refrain from evaluation single effects based on any threshold of statistical significance.

\section{Comparisons with existing literature}

Our results may indicate that the system itself-including all public primary healthcare GP services-usually is robust and capable of absorbing discontinuities without detrimental effects on most patient groups. The observed dip in GP consultations during the discontinuity was transient, indicating that after a few months, most patients were able to consult a GP in the same manner as before the break. However, our results also raise several concerns regarding the observed increase in emergency healthcare usage.

The increase in monthly odds of out-of-hours consultations seen during the break persisted throughout the follow-up period for several age groups. This may indicate suboptimal quality of care due to temporary solutions and delayed replacement of a new GP and/or that patients have a lower threshold for using the out-of-hours services when the alternative is seeing a locum/unknown GP.

The present study also indicates a small increase in ACSC admissions after the discontinuity for older patients. A relationship between interpersonal continuity of care, improved delivery of preventive services and lower rates of hospitalisation has been suggested by other studies. ${ }^{9}$ Our findings are also coherent with findings from recent large cross-sectional and cohort studies on older patients in other settings, indicating that a lower degree of continuity of care assessed by various indexes for continuity of care is associated with increased risk of hospital admission. ${ }^{5}{ }^{10}$ Increase in hospital admission could indicate a health deterioration due to lack of proper treatment and follow-up in the absence of the GP, but may also reflect that patients are more likely to be admitted to hospital when meeting unfamiliar doctors. A potential direct negative impact on patient health (and not only an overuse of secondary healthcare) is suggested by the findings of increased mortality with lower levels of continuity of care from other studies. ${ }^{19}$

In contrast to the large body of research on continuity of care, few studies have investigated cessation of continuity of care. A recent systematic review assessed how physician 


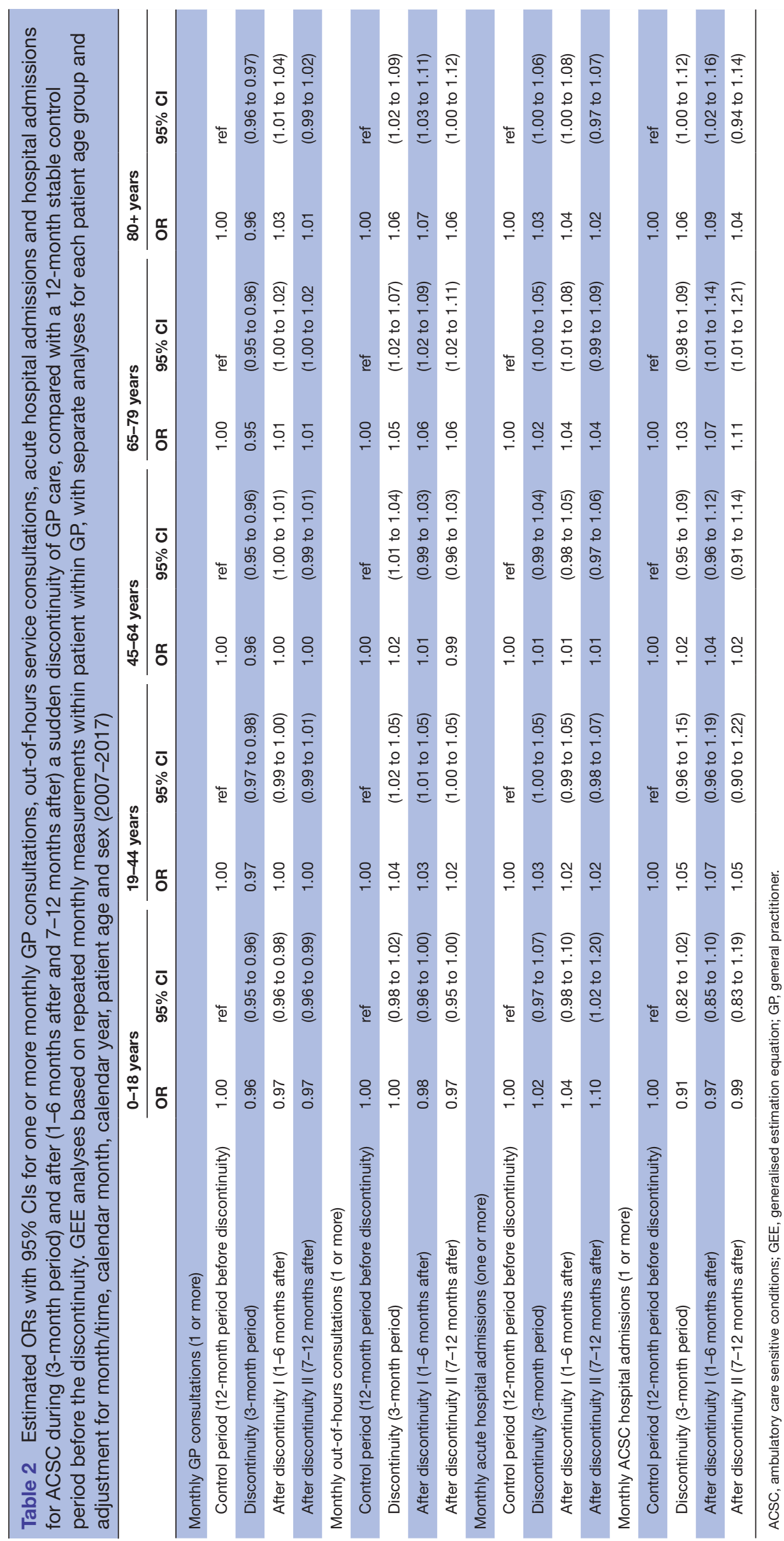


retirement impacted patients and found mainly unfavourable outcomes, mainly published as anecdotes and qualitative studies. $^{2}$ The authors point to some possible mechanisms related to difficulty accessing care, difficulty with transition and poor handover of information. Our results indicate that special attention should be given to elderly and frail patient groups as early as possible when the discontinuity is known to happen. Systematic identification of patients at risk and well-established information routines in relation to permanent or temporary GP breaks are possible actions that need to be studied further.

\section{CONCLUSION}

We investigated the consequences, in terms of health service use, for patients who experienced discontinuity of care from a primary physician who knew their medical and socioeconomic history. We found that in the Norwegian setting, discontinuity of GP care had some minor influence on primary care physician use. Patients continue to consult other GPs in a similar way as before and use the out-of-hours GP services to compensate for reduced access to or quality of care. Discontinuity of GP care might increase acute hospital admissions for ACSC in the older age groups, suggesting a crucial role of the GP for these patient groups. These findings underline the importance of continuity of care in order to keep patient care and costs on the lowest level desired, avoiding some unnecessary healthcare use (including out-of-hours visits and hospital admissions) and healthcare costs. This seems particularly important in the perspective of an ageing population since the older age groups seem most sensitive to GP continuity.

Acknowledgements We would like to thank Statistics Norway and the Norwegian Directorate of Health for providing data.

Contributors KP, JHB, LJS and SLK conceived the study and its design. KP and $\mathrm{JHB}$ contributed to design of the study protocol and facilitated acquisition of all data. KP and LJS prepared and analysed the data. JHB and SLK provided input on the discussion and interpretation of the findings. LJS drafted the first version of the manuscript. All authors contributed to and approved the final manuscript. All the authors have read the final version of the manuscript and agreed to its submission.

Funding This work was supported by the Norwegian University of Science and Technology and is a part of a larger project 'Healthcare services under pressureConsequences for patient flows, efficiency and patient safety in Norway' funded by the Norwegian Research Council (grant number 256579). JHB was funded by the Norwegian Research Council (grant number 295989).

Competing interests None declared.

Patient consent for publication Not required

Ethics approval The Regional Committee for Medical and Health Research Ethics in Central Norway approved the study (2011/2047).

Provenance and peer review Not commissioned; externally peer reviewed.

Data availability statement Data may be obtained from a third party and are not publicly available. The data used in this study are publicly available, given approval.

Supplemental material This content has been supplied by the author(s). It has not been vetted by BMJ Publishing Group Limited (BMJ) and may not have been peer-reviewed. Any opinions or recommendations discussed are solely those of the author(s) and are not endorsed by BMJ. BMJ disclaims all liability and responsibility arising from any reliance placed on the content. Where the content includes any translated material, BMJ does not warrant the accuracy and reliability of the translations (including but not limited to local regulations, clinical guidelines, terminology, drug names and drug dosages), and is not responsible for any error and/or omissions arising from translation and adaptation or otherwise.

Open access This is an open access article distributed in accordance with the Creative Commons Attribution Non Commercial (CC BY-NC 4.0) license, which permits others to distribute, remix, adapt, build upon this work non-commercially, and license their derivative works on different terms, provided the original work is properly cited, appropriate credit is given, any changes made indicated, and the use is non-commercial. See: http://creativecommons.org/licenses/by-nc/4.0/.

ORCID iD

Lena Janita Skarshaug http://orcid.org/0000-0002-1539-4853

\section{REFERENCES}

1 Freeman T, Brown JB, Reid G, et al. Patients' perceptions on losing access to fps: qualitative study. Can Fam Physician 2013:59:e195-201.

2 Lam K, Arnold CG, Savage RD, et al. Does physician retirement affect patients? A systematic review. J Am Geriatr Soc 2020;68:641-9.

3 Flocke SA, Stange KC, Zyzanski SJ. The impact of insurance type and forced discontinuity on the delivery of primary care. J Fam Pract 1997;45:129-35

4 Haggerty JL, Reid RJ, Freeman GK, et al. Continuity of care: a multidisciplinary review. BMJ 2003;327:1219-21.

5 Barker I, Steventon A, Deeny SR. Association between continuity of care in general practice and hospital admissions for ambulatory care sensitive conditions: cross sectional study of routinely collected, person level data. BMJ 2017;356:j84.

6 Bayliss EA, Ellis JL, Shoup JA, et al. Effect of continuity of care on hospital utilization for seniors with multiple medical conditions in an integrated health care system. Ann Fam Med 2015;13:123-9.

7 Hansen AH, Halvorsen PA, Aaraas IJ, et al. Continuity of GP care is related to reduced specialist healthcare use: a cross-sectional survey. Br J Gen Pract 2013;63:e482-9.

8 Huntley A, Lasserson D, Wye L, et al. Which features of primary care affect unscheduled secondary care use? A systematic review. BMJ Open 2014;4:e004746.

9 Saultz JW, Lochner J. Interpersonal continuity of care and care outcomes: a critical review. Ann Fam Med 2005;3:159-66.

10 Tammes P, Purdy S, Salisbury C, et al. Continuity of primary care and emergency hospital admissions among older patients in England. Ann Fam Med 2017;15:515-22.

11 van Loenen T, van den Berg MJ, Westert GP, et al. Organizational aspects of primary care related to avoidable hospitalization: a systematic review. Fam Pract 2014;31:502-16.

12 Menec VH, Sirski M, Attawar D, et al. Does continuity of care with a family physician reduce hospitalizations among older adults? $J$ Health Serv Res Policy 2006;11:196-201.

13 Swanson JO, Vogt V, Sundmacher L, et al. Continuity of care and its effect on readmissions for COPD patients: a comparative study of Norway and Germany. Health Policy 2018;122:737-45.

14 Emery DP, Milne T, Gilchrist CA, et al. The impact of primary care on emergency department presentation and hospital admission with pneumonia: a case-control study of preschool-aged children. NPJ Prim Care Respir Med 2015;25:14113.

15 Kohnke H, Zielinski A. Association between continuity of care in Swedish primary care and emergency services utilisation: a population-based cross-sectional study. Scand J Prim Health Care 2017;35:113-9.

16 Sarmento G, Leal-Seabra F, Brinquinho M. Continuity of primary care and emergency department utilization among elderly people. European Geriatric Medicine 2016;7:S224.

17 Leleu H, Minvielle E. Relationship between longitudinal continuity of primary care and likelihood of death: analysis of national insurance data. PLoS One 2013;8:e71669.

18 Maarsingh OR, Henry Y, van de Ven PM, et al. Continuity of care in primary care and association with survival in older people: a 17-year prospective cohort study. Br J Gen Pract 2016;66:e531-9.

19 Pereira Gray DJ, Sidaway-Lee K, White E, et al. Continuity of care with Doctors-a matter of life and death? A systematic review of continuity of care and mortality. BMJ Open 2018;8:e021161.

20 Wolinsky FD, Bentler SE, Liu L, et al. Continuity of care with a primary care physician and mortality in older adults. J Gerontol A Biol Sci Med Sci 2010;65:421-8.

21 Hollander MJ, Kadlec H. Financial implications of the continuity of primary care. Perm J 2015;19:4-10. 
22 The Norwegian Ministry of Health and Care Services. Forskrift Om fastlegeordning I kommunene 2012, 2018. Available: https://lovdata. no/dokument/SF/forskrift/2012-08-29-842 [Accessed 16 May 2020].

23 The Norwegian Medical Association, The Norwegian Association of General Practitioners, The Medical Speciality Society for General Practice. Utviklingsplan for fastlegeordningen 2015 - 2020, 2015. Available: https://www.legeforeningen.no/contentassets/743cd468 b6d6435ca138de1a2909caf9/utviklingsplan-flo.pdf [Accessed 19 May 2020].

24 Hetlevik Øystein, Gjesdal S. Personal continuity of care in Norwegian general practice: a national cross-sectional study. Scand J Prim Health Care 2012;30:214-21.

25 Greenfield G, Foley K, Majeed A. Rethinking primary care's gatekeeper role. BMJ 2016;354:i4803.

26 EY and Vista Analysis. Evaluering AV fastlegeordningen, 2019. Available: https://www.regjeringen.no/contentassets/7cd212bf 5f0642c1a5d0d480f0923e6d/evaluering-av-fastlegeordningensluttrapport-fra-ey-og-vista-analyse.pdf [Accessed 16 May 2020].

27 PØ G. Fastlegestatistikk 2018 hovedtall the Norwegian Directorate of health, 2019. Available: https://www.helsedirektoratet.no/statistikk/ fastlegestatistikk [Accessed 16 May 2020].

28 Statistics Norway. Statistisk sentralbyrå, 2019. Available: https:// www.ssb.no/en [Accessed 16 May 2020]

29 The Norwegian Directorate of Health. KUHR-databasen 2019, 2019. Available: https://www.helsedirektoratet.no/tema/statistikk-registreog-rapporter/helsedata-og-helseregistre/kuhr [Accessed 16 May 2020].
30 The Norwegian Directorate of eHealth. Fastlegeregisteret, 2020. Available: https://helsedata.no/forvaltere/helsedirektoratet/ fastlegeregisteret/ [Accessed 19 Mai 2020].

31 Bakken IJ, Ariansen AMS, Knudsen GP, et al. The Norwegian patient registry and the Norwegian Registry for primary health care: research potential of two nationwide health-care registries. Scand J Public Health 2020;48:1403494819859737.

32 The Norwegian Medical Association. Normaltariffen for fastleger og legevakt 2019-2020 [Tariff], 2019. Available: https://normaltariffen. legeforeningen.no/asset/pdf/Fastlegetariffen-2019-2020.pdf [Accessed 16 May 2020].

33 Ansari Z. The concept and usefulness of ambulatory care sensitive conditions as indicators of quality and access to primary health care. Aust J Prim Health 2007;13:91-110.

34 NHS Digital. Ambulatory care sensitive conditions (ACSC) 2019 , 2019. Available: https://digital.nhs.uk/data-and-information/datatools-and-services/data-services/innovative-uses-of-data/demandon-healthcare/ambulatory-care-sensitive-conditions\# [Accessed 16 May 2020]

35 Twisk JWR. Applied longitudinal data analysis for epidemiology. Cambridge: Cambridge University Press, 2003: 182.

36 PØ G. Fastlegestatistikk 2017 hovedtall [Regular General Practitioner Statistics 2017]: The Norwegian Directorate for Health, 2018. Available: https://www.helsedirektoratet.no/statistikk/statistikk/ fastlegestatistikk

37 Rothman KJ. Epidemiology: an introduction. 2nd edn. New Yourk: Oxford university press, 2012: 268. 